\title{
Common reed accumulates starch in its stem by metabolic adaptation under Cd stress conditions
}

\author{
Kyoko Higuchi ${ }^{1 *}$, Masatake Kanai ${ }^{1+}$, Masahisa Tsuchiya ${ }^{1}$, Haruka Ishii ${ }^{1}$, Naofumi Shibuya ${ }^{1}$, \\ Naoko Fujita ${ }^{2}$, Yasunori Nakamura ${ }^{2}$, Nobuo Suzui ${ }^{3}$, Shu Fujimaki ${ }^{3}$ and Eitaro Miwa ${ }^{1}$ \\ 1 Department of Applied Biology and Chemistry, Tokyo University of Agriculture, Setagaya-ku, Japan, ${ }^{2}$ Department of \\ Biological Production, Akita Prefectural University, Akita City, Japan, ${ }^{3}$ Medical and Biotechnological Application Division, \\ Quantum Beam Science Center, Japan Atomic Energy Agency, Takasaki City, Japan
}

OPEN ACCESS

Edited by:

David W. M. Leung

University of Canterbury, New Zealand

Reviewed by:

Gaëlle Saladin,

University of Limoges, France

Daniela Di Baccio,

National Research Council - IBAF, Italy

*Correspondence:

Kyoko Higuchi,

Department of Applied Biology and

Chemistry, Tokyo University of

Agriculture, Sakuragaoka 1-1-1, Setagaya-ku, Tokyo 156-8502, Japan

khiguchi@nodai.ac.jp

${ }^{\dagger}$ Present Address: Masatake Kanai,

Laboratory of Biological Diversity,

National Institute for Basic Biology,

Okazaki City, Japan

Specialty section:

This article was submitted to Plant Biotechnology, a section of the journal Frontiers in Plant Science

Received: 15 September 2014 Accepted: 20 February 2015

Published: 10 March 2015

Citation:

Higuchi K, Kanai M, Tsuchiya M, Ishii H, Shibuya N, Fujita N, Nakamura Y,

Suzui N, Fujimaki S and Miwa E (2015)

Common reed accumulates starch in its stem by metabolic adaptation under $\mathrm{Cd}$ stress conditions.

Front. Plant Sci. 6:138 doi: $10.3389 / \mathrm{fpls} .2015 .00138$
In a previous study, we reported that the common reed accumulates water-soluble Cd complexed with an $\alpha$-glucan-like molecule, and that the synthesis of this molecule is induced in the stem of the common reed under Cd stress. We studied the metabolic background to ensure $\alpha$-glucan accumulation under the $\mathrm{Cd}$ stress conditions that generally inhibit photosynthesis. We found that the common reed maintained an adequate $\mathrm{CO}_{2}$ assimilation rate, tended to allocate more assimilated ${ }^{11} \mathrm{C}$ to the stem, and accumulated starch granules in its stem under $\mathrm{Cd}$ stress conditions. AGPase activity, which is the rate-limiting enzyme for starch synthesis, increased in the stem of common reed grown in the presence of $\mathrm{Cd}$. Starch accumulation in the stem of common reed was not obvious under other excess metal conditions. Common reed may preferentially allocate assimilated carbon as the carbon source for the formation of $\mathrm{Cd}$ and $\alpha$-glucan complexes in its stem followed by prevention of Cd transfer to leaves acting as the photosynthetic organ. These responses may allow the common reed to grow even under severe Cd stress conditions.

Keywords: AGPase, $\alpha$-amylase, ${ }^{11} \mathrm{CO}_{2}$ tracer, $\mathrm{Cd}$, common reed, starch

\section{Introduction}

Common reed (Phragmites australis [(Cav.) Trin. ex Steudel]) is resistant to various abiotic stresses and has a large biomass (Mal and Narine, 2004). Responses of common reed to NaCl-salinity (Matoh et al., 1988; Kanai et al., 2007; Liu et al., 2012), drought (Pagter et al., 2005; Liu et al., 2012), and heavy metals (Wang and Peverly, 1996; Ye et al., 1997; Bonanno, 2011) have been investigated.

Common reed is not a heavy-metal hyper-accumulator, and the $\mathrm{Cd}$ content in its shoot is often less than that in other wetland plants (Stoltz and Greger, 2002; Ali et al., 2004). However, common reed has been proposed as a candidate plant for rhizofiltration, because of its large biomass and ability to accumulate $\mathrm{Cd}$ in its roots, consequently, decreasing the $\mathrm{Cd}$ concentration in water (Ali et al., 2004). Therefore, the mechanisms responsible for Cd tolerance in common reed have been investigated. In the roots, the increase of phytochelatins, lignin deposition, and unknown proteins were reported to be involved in Cd tolerance (Ederli et al., 2004; Jiang and Wang, 2007). In the shoot, the activities of antioxidant enzymes and amount of glutathione were found to be increased by Cd (Fediuc and Erdei, 2002; Pietrini et al., 2003), similar to that found in other plants (Gill and Tuteja, 2011). 
On the other hand, we reported a novel Cd-associated and $\mathrm{Cd}$-induced molecule in the stem of the common reed (Higuchi et al., 2013). In association with $\mathrm{Cd}$, this molecule is soluble and its major component is assumed to be an $\alpha$-glucan (Higuchi et al., 2013). This is in contrast to rice in which decreased distribution of $\mathrm{Cd}$ in the soluble fraction has been reported and is thought to be responsible for increased Cd tolerance (Xiong et al., 2009). Moreover, photosynthesis is generally inhibited by excess Cd (Gallego et al., 2012; Parmar et al., 2013), and thus, it seems to be difficult for the common reed to accumulate $\alpha$-glucan when grown with $\mathrm{Cd}$. Furthermore, the net photosynthetic rate is reduced by Cd (Mobin and Khan, 2007; Ying et al., 2010).

In this study, we demonstrate carbon assimilation and retranslocation; the increase of AGPase activity, which is the ratelimiting enzyme for starch synthesis; and the accumulation of starch granules in the stem of common reed grown with $\mathrm{Cd}$. These responses seem to be related to the supply of substrate for the synthesis of $\alpha$-glucan-like molecules that are associated with Cd.

\section{Materials and Methods}

\section{Plant Materials}

Plants were cultivated in a greenhouse maintained at $24-28^{\circ} \mathrm{C}$ under natural light. The composition of the standard nutrient solution was $1 \mathrm{mM}\left(\mathrm{NH}_{4}\right)_{2} \mathrm{SO}_{4}, 0.5 \mathrm{mM} \mathrm{KCl}, 0.25 \mathrm{mM} \mathrm{K}_{2} \mathrm{HPO}_{4}$, $0.5 \mathrm{mM} \mathrm{CaCl}_{2}, 0.5 \mathrm{mM} \mathrm{MgCl}_{2}, 90 \mu \mathrm{M}$ Fe-EDTA, $46 \mu \mathrm{M} \mathrm{H}_{3} \mathrm{BO}_{3}$, $9.2 \mu \mathrm{M} \mathrm{MnCl}_{2}, 0.32 \mu \mathrm{M} \mathrm{CuSO}_{4}, 0.77 \mu \mathrm{M} \mathrm{ZnSO}_{4}$, and $0.08 \mu \mathrm{M}$ $\left(\mathrm{NH}_{4}\right)_{6} \mathrm{Mo}_{7} \mathrm{O}_{24}$. The $\mathrm{pH}$ of the nutrient solution was adjusted to 5.5 by the addition of $\mathrm{HCl}$, and the solution was changed every 3 d. Seeds of common reed collected in Hokkaido Prefecture (Japan) were purchased from Snow Brand Seed Co., Ltd. (Sapporo, Japan). The seeds were germinated on gauze floating in tap water; seedlings that grew to a height of 1-2 cm were transferred to a half-strength nutrient solution, and those that grew to a height of $5-6 \mathrm{~cm}$ were transferred to a full-strength nutrient solution in 5-L plastic containers. Seedlings that grew to $20 \mathrm{~cm}$ in height were used in subsequent experiments. For comparison of starch accumulation among several heavy metal stresses, $50 \mu \mathrm{M}$ $\mathrm{CdCl}_{2}, \mathrm{MnCl}_{2}, \mathrm{CuCl}_{2}, \mathrm{NiCl}_{2}$, or $\mathrm{ZnCl}_{2}$ were added to the nutrient solution for $12 \mathrm{~d}$. For other experiments, plants were grown with $10 \mu \mathrm{M} \mathrm{CdCl}_{2}$. Plants were sampled at approximately noon and stored at $-80^{\circ} \mathrm{C}$ for subsequent assay of enzyme activity or were dried for starch measurements.

\section{Starch Determination}

The starch content of plant tissues was determined using an assay described by Wong et al. (2003). Briefly, dried plant tissues were ground using a mortar and pestle. Five to ten milligrams of ground powder was washed twice in $1 \mathrm{~mL}$ methanol, and then twice in $1 \mathrm{~mL}$ distilled water. The precipitate was suspended in $0.5 \mathrm{~mL}$ distilled water and heated in a boiling water bath for $2 \mathrm{~h}$. The final volume was adjusted to $1 \mathrm{~mL}$ with distilled water. The amount of starch was determined by the method described by Bergmeyer et al. (1974). To $100 \mu \mathrm{L}$ of the above solution, $100 \mu \mathrm{L}$ of $50 \mathrm{mM} \mathrm{Na}$-acetate buffer (pH 5.0) was added, followed by 50 nkat of glucoamylase (EC 3.2.1.3., Rhizopus niveus, Seikagaku co.,
Tokyo, Japan), and 5 nkat $\alpha$-amylase ultrapure (EC3.2.1.1, Nippon Gene, Tokyo, Japan). This solution was mixed and incubated for $1 \mathrm{~h}$ at $25^{\circ} \mathrm{C}$, then for $1 \mathrm{~h}$ at $60^{\circ} \mathrm{C}$, and was then centrifuged at $10,000 \times g$ for $10 \mathrm{~min}$. Next, the supernatant $(200 \mu \mathrm{L})$ was mixed with $800 \mu \mathrm{L}$ of a solution consisting of $60 \mathrm{mM}$ HEPES$\mathrm{KOH}$ (pH 7.4), $5 \mathrm{mM} \mathrm{MgCl}_{2}, 2 \mathrm{mM} \mathrm{NADP}$, and $25 \mathrm{mM}$ ATP. The amount of glucose in the solution was determined by the increase in absorbance at $340 \mathrm{~nm}$ after the addition of $1 \mathrm{~mL}$ each of hexokinase (EC 2.7.1.1, 2.8 nkat, Roche Diagnostics Japan, Tokyo, Japan) and G6P dehydrogenase (EC 1.1.1.49, 2.3 nkat, Roche Diagnostics Japan).

\section{Enzymatic Activity}

Frozen plant tissues were ground using a mortar and pestle with liquid $\mathrm{N}_{2}$. The protein content of samples was estimated using a Protein Assay Kit with Standard I based on the Bradford method (Bio Rad, Hercules, CA, USA). For AGPase (EC 2.7.7.27) activity, we used the method reported by Nakamura et al. (1989). Phosphoglucomutase (EC 5.4.2.2) was purchased from Sigma-Aldrich (St. Louis, MO, USA).

\section{Photosynthetic Rate}

Intact leaves from common reed plants growing in a greenhouse were used to measure the photosynthetic rate. Leaf gas exchange was measured using an open gas-exchange system (LI6400XT; LI-COR Inc., Lincoln, NE, USA) with an integrated fluorescence chamber head (LI-6400-40 leaf chamber fluorimeter; LI-COR Inc.). The $\mathrm{CO}_{2}$ assimilation rate $\left(\mu \mathrm{mol} \mathrm{CO} \mathrm{m}^{-2} \cdot \mathrm{s}^{-1}\right)$ was measured using the stored program of the light-curve mode of LI-6400. Parameters were set as follows: TempR (relative temperature $)=20^{\circ} \mathrm{C}, \mathrm{CO}_{2} \mathrm{R}$ (relative $\mathrm{CO}_{2}$ concentration) $=$ $400 \mu \mathrm{mol} \mathrm{m} \mathrm{m}^{-2} \cdot \mathrm{s}^{-1}$, flow $=500 \mu \mathrm{mol} \cdot \mathrm{s}^{-1}$, and PQntm (light intensity and quality) $=500 \mu \mathrm{mol}$ photon $\mathrm{m}^{-2} \cdot \mathrm{s}^{-1}$ (containing $10 \%$ blue light).

\section{${ }^{11}$ C-Assimilation}

We performed real-time and non-destructive imaging of ${ }^{11} \mathrm{C}$ assimilate dynamics in intact common reed plants using a positron-emitting tracer imaging system (PETIS). The upper part of young leaves from three common reed plants was inserted into a sealed acrylic compartment (inner volume: $432 \mathrm{~mL}$ ), and other parts of the plants, including leaf sheaths, stems, and roots were set within the field of view $(120 \mathrm{~mm}$ width $\times 187 \mathrm{~mm}$ height) of the PETIS apparatus (a modified PPIS-4800 model; Hamamatsu Photonics, Hamamatsu, Japan). ${ }^{11} \mathrm{CO}_{2}$ (half-life: $20.4 \mathrm{~min}$ ) gas was synthesized using an energetic proton beam delivered from an AVF cyclotron located at Takasaki Ion Accelerators for Advanced Radiation Application, Japan Atomic Energy Agency, following the method described by Ishioka et al. (1999). After $100 \mathrm{MBq}$ of ${ }^{11} \mathrm{CO}_{2}$ gas with ambient air was fed into the compartment at a flow rate of $400 \mathrm{~mL} \cdot \mathrm{min}^{-1}$, serial images of ${ }^{11} \mathrm{C}$-assimilates in plants were acquired every $10 \mathrm{~s}$ for $2 \mathrm{~h}$ using PETIS. All experiments were performed in a growth chamber under controlled conditions at $28^{\circ} \mathrm{C}$ and $65 \%$ relative humidity. Light was maintained at a photon flux density of approximately $400 \mu \mathrm{mol}$ photon $\mathrm{m}^{-2} \cdot \mathrm{s}^{-1}$ on the young leaf using a light-emitting diode (LED) light source (ISL-150X150-HWW; 
CCS Incorporated, Kyoto, Japan). Using NIH ImageJ 1.49 e software (http://rsb.info.nih.gov/ij/, 2 August 2014), regions of interest (ROIs) were manually selected on each image, and the time course of ${ }^{11} \mathrm{C}$-radioactivity in the ROIs was calculated.

\section{Results}

\section{Common Reed Can Supply Sufficient Carbon Assimilates to its Stem Under Cd Stress}

We analyzed the ability of common reed to assimilate and allocate carbon under conditions of $10 \mu \mathrm{M}$ Cd stress. By day 3 of the Cd treatment, the Cd concentration of the leaves increased noticeably (data not shown). First, we measured the $\mathrm{CO}_{2}$ assimilation rate under $\mathrm{Cd}$ stress. The $\mathrm{CO}_{2}$ assimilation rates of mature leaves were slightly but not significantly decreased during the 3 $\mathrm{d}$ of $\mathrm{Cd}$ stress, and were comparable to those in control leaves (Figure 1). The $\mathrm{CO}_{2}$ assimilation rates of young leaves were not affected by $\mathrm{Cd}$ (Figure 1). Although we confirmed leaf chlorosis and growth reduction in common reed induced by 2-4 weeks of $\mathrm{Cd}$ treatment, the leaves survived and continued to grow (data not shown).

Next, we monitored the allocation of assimilated carbon. Using a combination of ${ }^{11} \mathrm{C}$, which has a half-life of $20 \mathrm{~min}$ and the real-time imaging method PETIS, repeated $\mathrm{CO}_{2}$ assimilation and allocation of assimilates in the same plant can be detected under different conditions. The use of this method is suitable for analyzing common reed that exhibits large individual differences in shape, for example, the development of tillers or the elongation of inter nodes. We supplied ${ }^{11} \mathrm{CO}_{2}$ to young leaves and monitored radioactivity for $2 \mathrm{~h}$, after which each plant was grown with or without $\mathrm{Cd}$ for $3 \mathrm{~d}$, before repeating the pulse labeling experiment (Supplementary Figure S1). Whole plant data (Figure 2) confirmed that the amount of assimilated carbon released from source leaves was not decreased by Cd stress. Carbon allocated

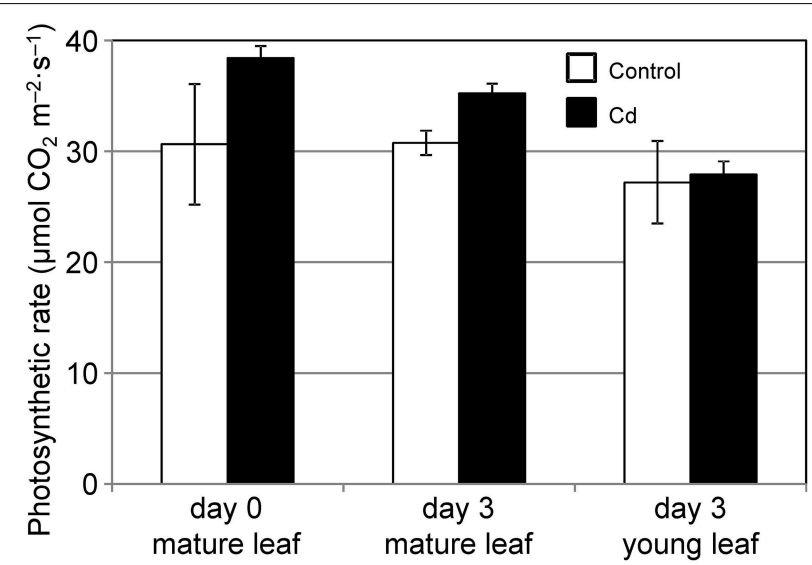

FIGURE 1 | $\mathbf{C O}_{2}$ assimilation rate at $\mathbf{5 0 0}$ PPFD under Cd stress. $\mathrm{CO}_{2}$ assimilation rates for a mature leaf just before (day 0 ), and mature and young leaves $3 \mathrm{~d}$ after (day 3 ) starting $10 \mu \mathrm{M}$ Cd stress were measured. White bars, control plants; black bars, Cd-treated plants. We used leaves from the same three plants at day 0 and day 3 . Data are represented as the mean \pm SE $(n=3)$. to the stem tended to decrease in control plants during the 3-d period, whereas it tended to increase in plants grown with $\mathrm{Cd}$ for $3 \mathrm{~d}$ (Figure 2). The allocation of carbon to roots was increased in both control and Cd-treated plants during the 3-d period (Figure 2). That is, $3 \mathrm{~d}$ of culture with Cd seemed to increase the allocation of carbon to the stem when compared to the control plants.

\section{Common Reed Accumulates Starch Granules in its Stem Under Cd Stress}

Starch serves as a temporary pool of carbon. Thus far, we have observed a large number of starch granules in the stem of common reed grown with $\mathrm{Cd}$. To investigate whether stress starch in stem has some special characteristics, we analyzed the shape and molecular structure of the starch present in stems. We collected starch granules from stems grown with $\mathrm{Cd}$, and from control stems that contained a small amount of starch. The shapes of starch granules observed by scanning electron microscopy were similar in the control and Cd-treated plants (Supplementary Figures S2B,C). The chain-length distribution of amylopectin in these starch granules also exhibited similar patterns (Supplementary Figure S2D). Thus, Cd stress induced the accumulation of normal starch granules in the stems of common reed.

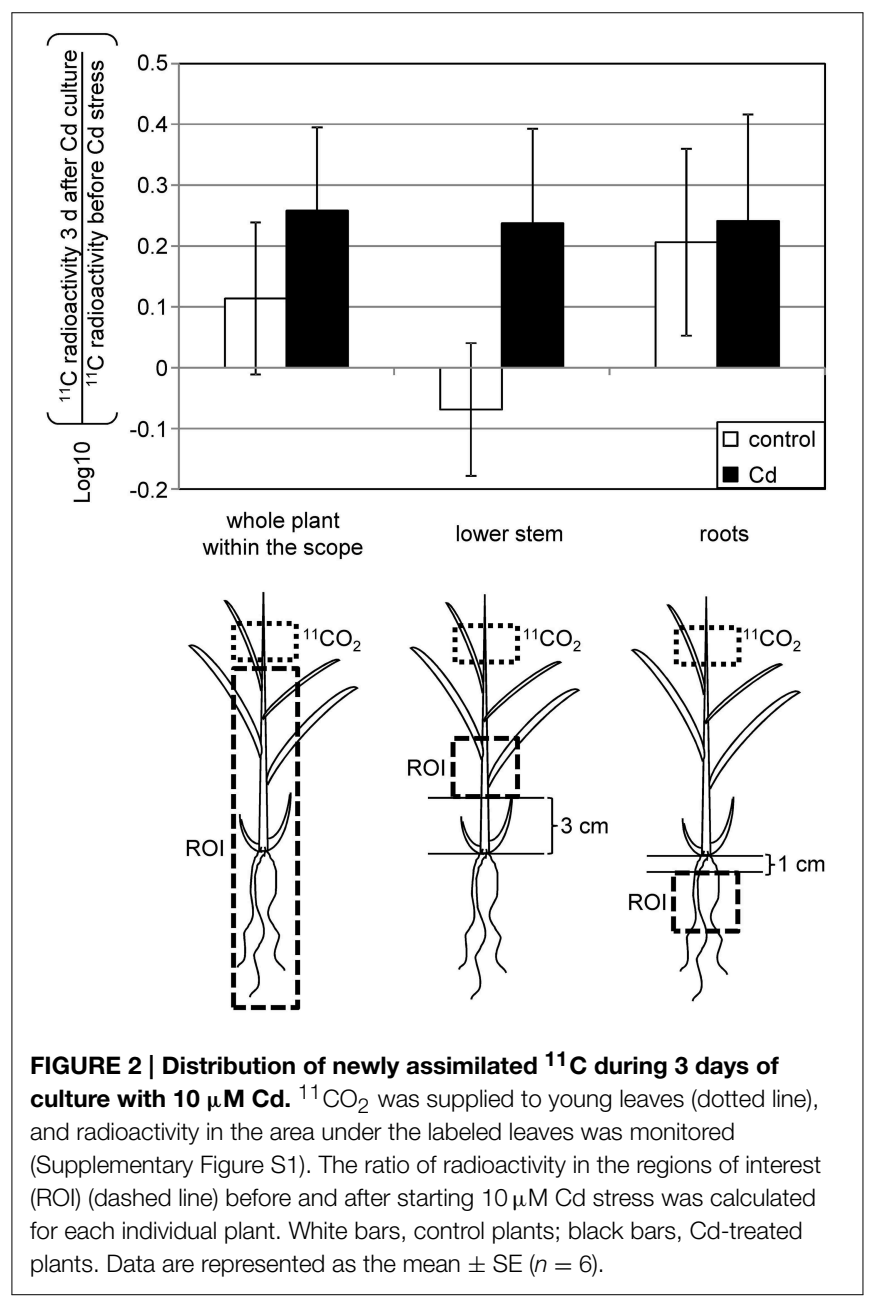


The accumulation of starch has previously been reported in plants under metal stress (Nyitrai et al., 2004; Zambrosi et al., 2013; Zappala et al., 2014); thus, we tested whether the accumulation of starch granules can be observed in the stem of common reed grown in the presence of other excess metals. To obtain a large number of starch granules that could be easily observed, we added $50 \mu \mathrm{M}$ of each heavy metal to the nutrient solution and cultured the plants for $12 \mathrm{~d}$. When grown with $\mathrm{Cd}$ or $\mathrm{Ni}$, plants were significantly shorter than the control plants $(P<0.05)$ (Supplementary Figure S3A); however, plants grew continuously and the symptoms of leaf chlorosis were mild. Thus, damage caused by $\mathrm{Cd}$ or $\mathrm{Ni}$ was not extreme when compared to plants grown with other metals. $\mathrm{Cd}, \mathrm{Cu}$, and $\mathrm{Zn}$ tended to accumulate more in stems than in leaves (Supplementary Figures S3B-F), especially Cd. A significant amount of starch accumulated in the leaves of all plants grown in the presence of excess heavy metals (Figure 3, hatched bars). However, the amount of starch in the stems of Cd treated plants was about three-fold higher than the amount in plants grown with other metals (Figure 3, black bars). Starch accumulation in stems grown with Cd was also clearly visible by iodine staining (Supplementary Figure S2A).

\section{Agpase Activity is Increased by Cd Stress in the Stem}

To investigate whether $\mathrm{Cd}$ triggers starch synthesis, we measured the activity of AGPase, which is the rate-limiting enzyme for starch synthesis. Although short-term culture of plants with $10 \mu \mathrm{M}$ Cd allows for the accumulation of only a small amount of starch granules, we tested common reed grown with $10 \mu \mathrm{M} \mathrm{Cd}$ over 7 days to determine how early common reed respond to $\mathrm{Cd}$. Starch levels tended to increase in stems under Cd stress, but the result was not significant (Figure 4B). The increase in AGPase activity in stems grown with $\mathrm{Cd}$ was significant (Figure 4E). One day of culture with Cd was sufficient to elevate AGPase activity. The amount of starch and AGPase activity in leaves tended to increase during culture with $\mathrm{Cd}$, but this was not always significant (Figures 4A,D). In roots, these factors were not affected by $\mathrm{Cd}$ (Figures $\mathbf{4 C , F}$ ). Common reed can grow under more severe $\mathrm{Cd}$ stress conditions. We confirmed the increase in starch amounts and AGPase activities in stem even under $100 \mu \mathrm{M} \mathrm{Cd}$ conditions (Supplementary Figure S4).

\section{Discussion}

In this study, we showed that common reed under Cd stress tends to allocate newly assimilated carbon to the stem when compared to that in control plants (Figure 2). In other words, the ratio of carbon distribution to the stem was not altered under Cd stress, but decreased in control plants during the 3-d experimental period (Supplementary Figure S5). The carbon source allocated to the stem might support the synthesis of $\alpha$-glucan-like molecules associated with $\mathrm{Cd}$, which are induced by excess $\mathrm{Cd}$ in the stem of common reed plants (Higuchi et al., 2013). In parallel, starch accumulates in the stem of the common reed grown with $\mathrm{Cd}$. The accumulation of starch has previously been reported in plants under metal stress. Tian et al. (2010) reported that the disturbance of $\mathrm{Na}$ and $\mathrm{K}$ homeostasis caused defects in phloem loading or translocation, and consequently caused accumulation of starch in Arabidopsis leaves. Excess Cu disturbed the development of chloroplasts, and starch granules accumulated in cotyledons of screwbean mesquite (Zappala et al., 2014). Low-dose Pb and $\mathrm{Ni}$, but not $\mathrm{Cd}$, increased the starch content in detached bean leaves (Nyitrai et al., 2004), and starch granules accumulated in damaged root cells of citrus due to excess $\mathrm{Cu}$ (Zambrosi et al., 2013). These previous studies suggest that metal stress disturbs the export or consumption of assimilates and leads to the accumulation of starch; however, export and allocation of assimilated ${ }^{11} \mathrm{C}$ from leaves to other parts of the plant was not decreased by $\mathrm{Cd}$ in common reed (Figure 2). Thus, starch accumulation in the stem of common reed seems to be an adaptive response, rather than a result of damage under excess Cd conditions. Abundant

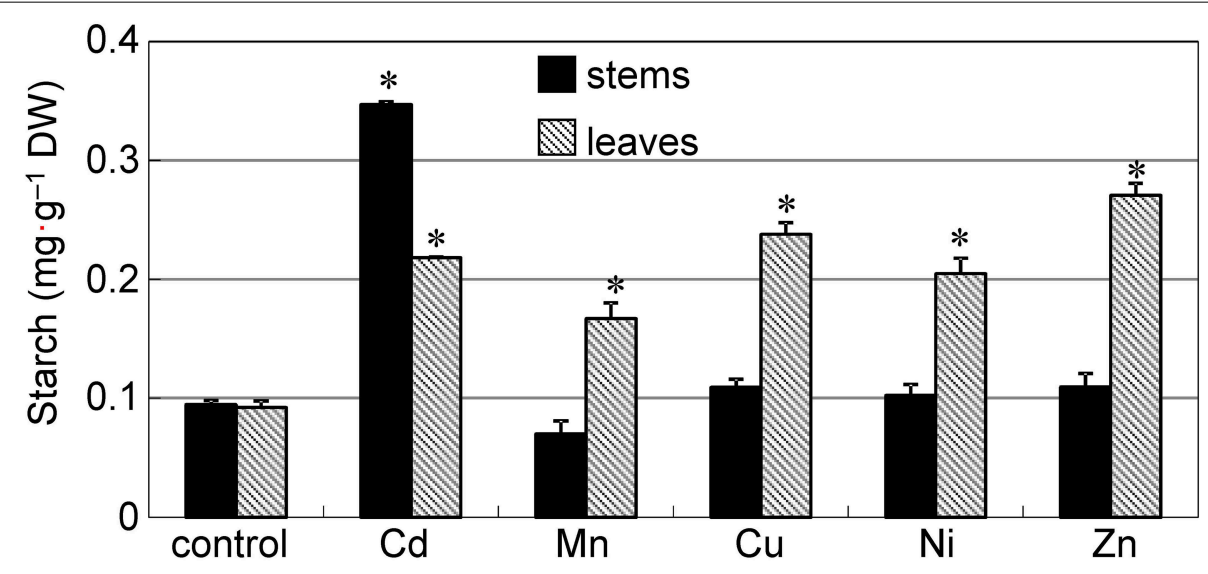

FIGURE 3 | Accumulation of starch in reed plants grown under excess heavy metal conditions. Seedlings were divided into six groups and transplanted into normal culture solution or solutions containing an excess of heavy metals $\left(50 \mu \mathrm{M} \mathrm{CdCl}, \mathrm{MnCl}_{2}, \mathrm{CuCl}_{2}\right.$,
$\mathrm{NiCl}_{2}$, or $\mathrm{ZnCl}_{2}$ ), where they were then grown for $12 \mathrm{~d}$. Black bar: stem. Hatched bar: leaves. Data are represented as the mean $\pm \mathrm{SE}$ $(n=3) .{ }^{*} P<0.05$ indicate significant differences (according to Dunnett's test). 

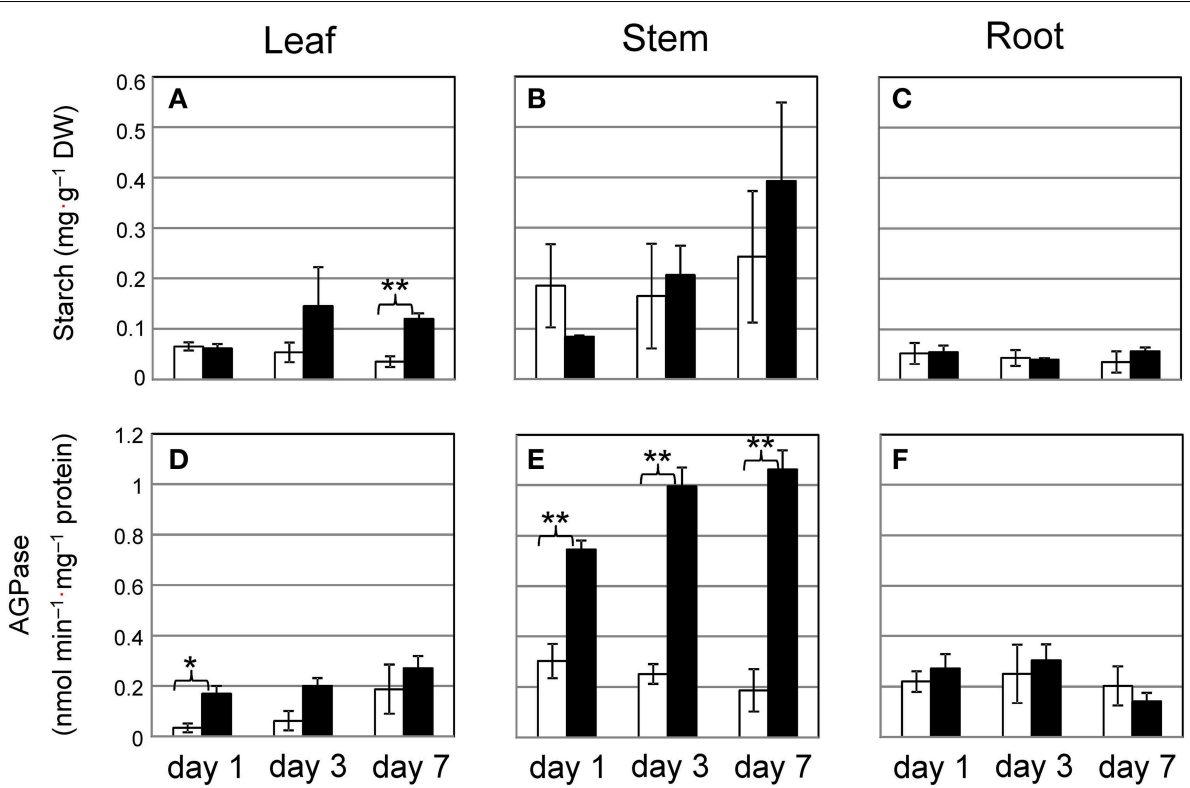

FIGURE 4 | Time course of starch accumulation and AGPase activity in common reed grown with $10 \mu \mathbf{M} \mathbf{C d}$. (A-C), Starch concentration; (D-F), AGPase activity. (A,D), leaf; (B,E), stem; (C,F), root. White bars, control plants; black bars, Cd-treated plants. Data are represented as the mean $\pm \operatorname{SE}(n=3) .{ }^{*} P<0.05$ and ${ }^{* *} P<0.01$ indicate significant differences (according to Student's $t$-test). carbon in the stem of common reed grown with Cd could be temporarily pooled as starch and utilized to synthesize $\alpha$-glucan-like molecules trapping Cd.

Both enzyme activity and supply of carbon control starch synthesis. AGPase is a key enzyme involved in starch synthesis (Preiss et al., 1991). AGPase activities increased in the stems of common reed grown with $\mathrm{Cd}$ within 1 day before the starch levels increased significantly (Figure 4). Common reed stimulated AGPase activity in stem even under $100 \mu \mathrm{M}$ Cd conditions (Supplementary Figure S4). This means that the primary carbon metabolism of common reed functions even under severe $\mathrm{Cd}$ stress conditions. A few studies reported the influence of mineral stress on AGPase in vegetative tissues. Chen et al. reported that AGPase activity in the leaves of rice seedlings slightly decreased under salt stress (Chen et al., 2008). Several studies discussed AGPase activity in the stems, which is important in the pooling of carbohydrates (Cook et al., 2012; Seferoglu et al., 2013), but upregulation of AGPase in the stems by mineral stress has not been reported. Whether Cd directly regulates enzymes involved in carbohydrate metabolism or indirectly influences carbon metabolism requires further study.

$\mathrm{Zn} / \mathrm{Cd}$ hyper-accumulator Picris divaricata could maintain a $\mathrm{CO}_{2}$ assimilation rate at $0.2 \mathrm{mg} \cdot \mathrm{g}^{-1}$ dry weight (DW) shoot $\mathrm{Cd}$ concentration (Ying et al., 2010). In the case of Brassica juncea,

\section{References}

Ali, N. A., Bernal, M. P., and Ater, M. (2004). Tolerance and bioaccumulation of cadmium by Phragmites australis grown in the presence of elevated the $\mathrm{CO}_{2}$ assimilation rate decreased when the $\mathrm{Cd}$ concentration in the leaves was higher than $0.05 \mathrm{mg} \cdot \mathrm{g}^{-1} \mathrm{DW}$ (Mobin and Khan, 2007). In this study, less than $0.01 \mathrm{mg} \cdot \mathrm{g}^{-1} \mathrm{DW}$ Cd was detected in the leaves used in Figures 1, 4. The leaves of common reed may not have developed a tolerance to Cd comparable to that of hyper-accumulators, and the low $\mathrm{Cd}$ concentration in the leaves may be a key factor in the maintenance of photosynthesis. However, we found more than $0.05 \mathrm{mg} \cdot \mathrm{g}^{-1} \mathrm{DW} \mathrm{Cd}$ in the stem used in Figure 4. Thus, amyloplasts/chloroplasts in the stem of common reed could have some mechanism for Cd tolerance.

\section{Acknowledgments}

This study was supported partly by a Grant-in-Aid for Scientific Research from the Ministry of Education, Culture, Sports, Science, and Technology, Japan [grant numbers 21380049 to K.H.].

\section{Supplementary Material}

The Supplementary Material for this article can be found online at: http://www.frontiersin.org/journal/10.3389/fpls.2015. 00138/abstract 
Analysis, Vol. 3, eds H. U. Bergmeyer and K. Gawehn (Weinheim: Verlag Chemie Weinheim), 1196-1201.

Bonanno, G. (2011). Trace element accumulation and distribution in the organs of Phragmites australis (common reed) and biomonitoring applications. Ecotoxicol. Environ. Saf. 74, 1057-1064. doi: 10.1016/j.ecoenv.2011.01.018

Chen, H. J., Chen, J. Y., and Wang, S. J. (2008). Molecular regulation of starch accumulation in rice seedling leaves in response to salt stress. Acta Physiol. Plant 30, 135-142. doi: 10.1007/s11738-007-0101-y

Cook, F. R., Fahy, B., and Trafford, K. (2012). A rice mutant lacking a large subunit of ADP-glucose pyrophosphorylase has drastically reduced starch content in the culm but normal plant morphology and yield. Funct. Plant Biol. 39, 1068-1078. doi: 10.1071/FP12186

Ederli, L., Reale, L., Ferranti, F., and Pasqualini, S. (2004). Responses induced by high concentration of cadmium in Phragmites australis roots. Physiol. Plant. 121, 66-74. doi: 10.1111/j.0031-9317.2004.00295.x

Fediuc, E., and Erdei, L. (2002). Physiological and biochemical aspects of cadmium toxicity and protective mechanisms induced in Phragmites australis and Typha latifolia. J. Plant Physiol. 159, 265-271. doi: 10.1078/0176-1617-00639

Gallego, S. M., Pena, L. B., Barcia, R. A., Azpilicueta, C. E., Iannone, M. F., Rosales, E. P., et al. (2012). Unravelling cadmium toxicity and tolerance in plants: insight into regulatory mechanisms. Environ. Exp. Bot. 83, 33-46. doi: 10.1016/j.envexpbot.2012.04.006

Gill, S. S., and Tuteja, N. (2011). Cadmium stress tolerance in crop plants - Probing the role of sulfur. Plant Signal. Behav. 6, 215-222. doi: 10.4161/psb.6.2. 14880

Higuchi, K., Tsuchiya, M., Nakata, S., Tanabe, A., Fukawa, S., Kanai, M., et al. (2013). Detoxification of cadmium (Cd) by a novel Cd-associated and Cdinduced molecule in the stem of common reed. J. Plant Physiol. 170, 1553-1560. doi: 10.1016/j.jplph.2013.06.009

Ishioka, N. S., Matsuoka, H., Watanabe, S., Osa, A., Koizumi, M., Kume, T., et al. (1999). Production of positron emitters and application of their labeled compounds to plant studies. J. Radioanal. Nucl. Chem. 239, 417-421. doi: 10.1007/BF02349523

Jiang, X., and Wang, C. (2007). Cadmium distribution and its effects on molybdate-containinghydroxylases in Phragmites australis. Aquat. Bot. 86, 353-360. doi: 10.1016/j.aquabot.2007.01.002

Kanai, M., Higuchi, K., Hagihara, T., Konishi, T., Ishii, T., Fujita, N., et al. (2007). Common reed produces starch granules at the shoot base in response to salt stress. New Phytol. 176, 572-580. doi: 10.1111/j.1469-8137.2007. 02188.x

Liu, Y., Li, X., Liu, M., Cao, B., Tan, H., Wang, J., et al. (2012). Responses of three different ecotypes of reed (Phragmites communis Trin.) to their natural habitats: leaf surface micro-morphology, anatomy, chloroplast ultrastructure and physio-chemical characteristics. Plant Physiol. Biochem. 51, 159-167. doi: 10.1016/j.plaphy.2011.11.002

Mal, T. K., and Narine, L. (2004). The biology of canadian weeds. 129. Phragmites australis (Cav.) Trin. ex Steud. Can. J. Plant Sci. 84, 365-396. doi: 10.4141/P01-172

Matoh, T., Matsushita, N., and Takahashi, E. (1988). Salt tolerance of the reed plant Phragmites communis. Physiol. Plant. 72, 8-14. doi: 10.1111/j.13993054.1988.tb06615.x

Mobin, M., and Khan, N. A. (2007). Photosynthetic activity, pigment composition and antioxidative response of two mustard (Brassica juncea) cultivars differing in photosynthetic capacity subjected to cadmium stress. J. Plant Physiol. 164, 601-610. doi: 10.1016/j.jplph.2006.03.003

Nakamura, Y., Yuki, K., Park, S. Y., and Ohya, T. (1989). Carbohydrate metabolism in the developing endosperm of rice grains. Plant Cell Physiol. 30, 833-839.

Nyitrai, P., Bóka, K., Gáspár, L., Sárvári, E., and Keresztes, A. (2004). Rejuvenation of ageing bean leaves under the effect of low-dose stressors. Plant Biol. 6, 708-714. doi: $10.1055 / \mathrm{s}-2004-830385$
Pagter, M., Bragato, C., and Brix, H. (2005). Tolerance and physiological responses of Phragmites australis to water deficit. Aquat. Bot. 81, 285-299. doi: 10.1016/j.aquabot.2005.01.002

Parmar, P., Kumari, N., and Sharma, V. (2013). Structural and functional alterations in photosynthetic apparatus of plants under cadmium stress. Bot. Stud. 54:45. doi: 10.1186/1999-3110-54-45

Pietrini, F., Iannelli, M. A., Pasqualini, S., and Massacci, A. (2003). Interaction of cadmiumwith glutathione and photosynthesis in developing leaves and chloro-plasts of Phragmites australis (Cav) Trin. ex Steudel. Plant Physiol. 133, 829-837. doi: 10.1104/pp.103.026518

Preiss, J., Ball, K., Smith-White, B., Iglesias, A., Kakefuda, G., and Li, L. (1991). Starch biosynthesis and its regulation. Biochem. Soc. Trans. 19, 539-547.

Seferoglu, A. B., Baris, I., Morgil, H., Tulum, I., Ozdas, S., Cevahir, G., et al. (2013). Transcriptional reugulation of the ADP-glucose pyrophosphorylase isoforms in the leaf and the stem under long and short photoperiod in lentil. Plant Sci. 205, 29-37. doi: 10.1016/j.plantsci.2013.01.006

Stoltz, E., and Greger, M. (2002). Accumulation properties of $\mathrm{As}, \mathrm{Cd}, \mathrm{Cu}, \mathrm{Pb}$ and $\mathrm{Zn}$ by four wetland plant species growing on submerged mine tailings. Environ. Exp. Bot. 47, 271-280. doi: 10.1016/S0098-8472(02)00002-3

Tian, H., Baxter, I. R., Lahner, B., Reinders, A., Salt, D. E., and Ward, J. M. (2010). Arabidopsis NPCC6/NaKR1 is a phloem mobile metal binding protein necessary for phloem function and root meristem maintenance. Plant Cell 22, 3963-3979. doi: 10.1105/tpc. 110.080010

Wang, T. G., and Peverly, J. H. (1996). Oxidation states and fractionation of plaque iron on roots of common reeds. Soil Sci. Soc. Am. J. 60, 323-329. doi: 10.2136/sssaj1996.03615995006000010049x

Wong, K. S., Kubo, A., Jane, J. L., Harada, K., Satoh, H., and Nakamura, Y. (2003). Structures and properties of amylopectin and phytoglycogen in the endosperm of sugary-1 mutant of rice. J. Cereal Sci. 37, 139-149. doi: $10.1006 /$ jcrs.2002.0485

Xiong, J., An, L., Lu, H., and Zhu, C. (2009). Exogenous nitric oxide enhances cadmium tolerance of rice by increasing pectin and hemicellulose contents in root cell wall. Planta 230, 755-765. doi: 10.1007/s00425-009-0984-5

Ye, Z. H., Baker, A. J. M., Wong, M. H., and Willis, A. J. (1997). Zinc, lead and cadmium tolerance, uptake and accumulation by the common reed, Phragmites australis (Cav.) Trin. ex Steudel. Ann. Bot. 80, 363-370. doi: 10.1006/anbo.1997.0456

Ying, R. R., Qiu, R. L., Tang, Y. T., Hu, P. J., Qiu, H., Chen, H. R., et al. (2010). Cadmium tolerance of carbon assimilation enzymes and chloroplast in $\mathrm{Zn} / \mathrm{Cd}$ hyperaccumulator Picris divaricata. J. Plant Physiol. 167, 81-87. doi: 10.1016/j.jplph.2009.07.005

Zambrosi, F. C. B., Mesquita, G. L., Tanaka, F. A. O., Quaggio, J. A., and Mattos, D. Jr. (2013). Phosphorus availability and rootstock affect copper-induced damage to the root ultra-structure of Citrus. Environ. Exp. Bot. 95, 25-33. doi: 10.1016/j.envexpbot.2013.07.004

Zappala, M. N., Ellzey, J. T., Bader, J., Peralta-Videa, J. R., and GardeaTorresdey, J. (2014). Effects of copper sulfate on seedlings of Prosopis pubescens (screwbean mesquite). Int. J. Phytoremed. 16, 1031-1041. doi: $10.1080 / 15226514.2013 .810582$

Conflict of Interest Statement: The authors declare that the research was conducted in the absence of any commercial or financial relationships that could be construed as a potential conflict of interest.

Copyright (๑) 2015 Higuchi, Kanai, Tsuchiya, Ishii, Shibuya, Fujita, Nakamura, Suzui, Fujimaki and Miwa. This is an open-access article distributed under the terms of the Creative Commons Attribution License (CC BY). The use, distribution or reproduction in other forums is permitted, provided the original author(s) or licensor are credited and that the original publication in this journal is cited, in accordance with accepted academic practice. No use, distribution or reproduction is permitted which does not comply with these terms. 